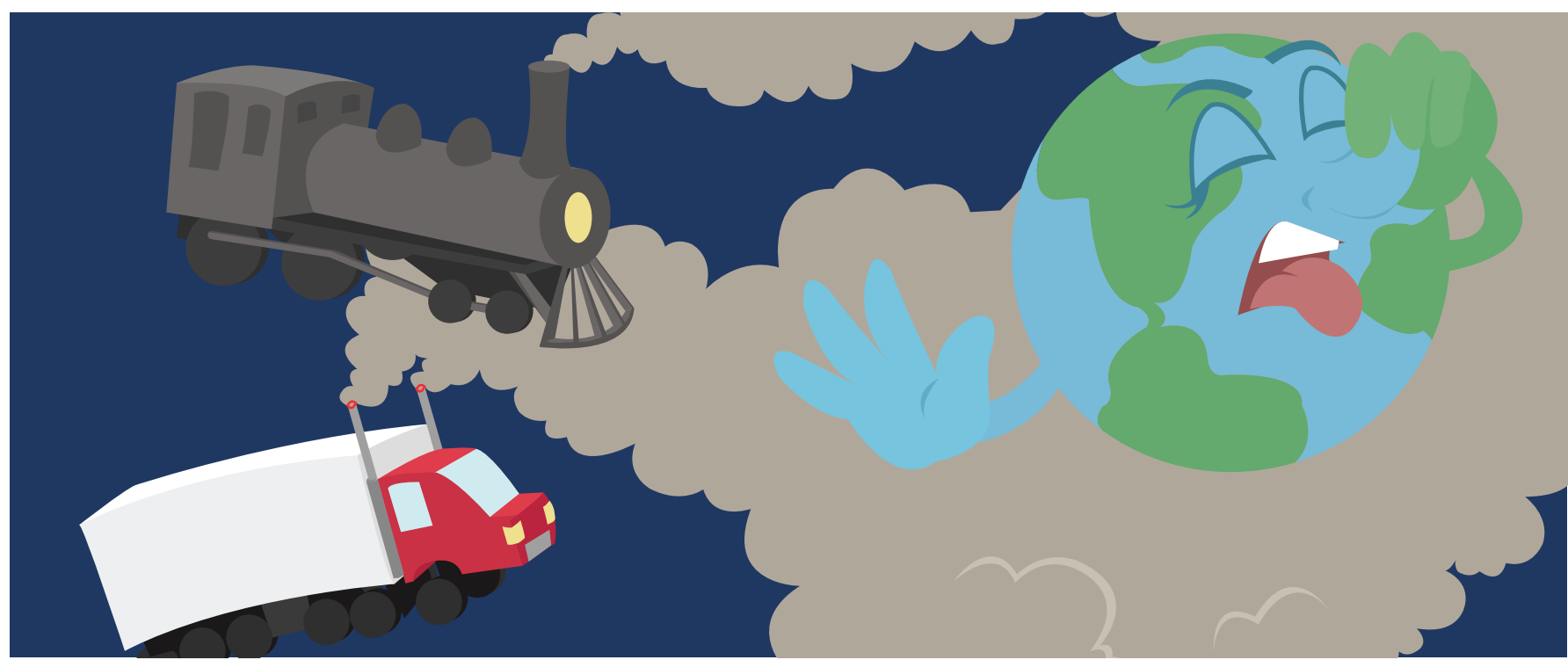

\title{
TRUCKS VERSUS TRAINS: HOW DOES THE WAY WE GET OUR STUFF AFFECT AIR
} POLLUTION?

\section{Alexandra Karambelas ${ }^{1 *}$ and Erica Bickford ${ }^{2}$}

${ }^{1}$ The Earth Institute, Columbia University, New York, NY, United States, ${ }^{2}$ US Department of Energy, Washington, DC, United States

\section{REVIEWED BY: \\ KIMBERLY AGE: 16 \\ AIR POLLUTION \\ Gaseous and particulate chemical compounds suspended in the atmosphere that can cause smog and affect human health.}

The air we breathe is composed of lots of different chemical components. Some of these components are pollutants that are harmful to human health. Air pollutants come from a variety of different sources, including power plants, factories, agriculture, and transportation. Transportation vehicles are powered by combustion of fossil fuels, such as gasoline or diesel, to move from one place to another, and combustion of these fuels results in the release of gases and very small particles. These substances are known as "pollution emissions." Different types of transportation can emit different amounts of air pollutants, which have an impact on local and regional air quality. Both trucks and trains are used to transport freight in the United States. Understanding how freight trucks and trains impact air quality is useful to learn ways to reduce pollution that is harmful to human health.

\section{WHAT IS AIR QUALITY AND WHY DOES IT MATTER?}

Air pollution is the presence of particulates (very small pieces of solid matter) and gases in the air, which are harmful for humans and the environment. 
EMISSIONS

Compounds released as byproducts when energy sources are burned.

NITROGEN OXIDES $\left(\mathrm{NO}_{x}\right)$

Gaseous chemical compounds consisting of nitrogen and oxygen, most commonly found in the atmosphere as nitrogen dioxide $\left(\mathrm{NO}_{2}\right)$ or nitrogen monoxide (NO).

\section{ELEMENTAL}

\section{CARBON (EC)}

Also known as black carbon, EC is dark soot emitted from incomplete combustion.

VOLATILE

ORGANIC

COMPOUNDS

(VOCS)

Gaseous chemical compounds consisting of at least one carbon molecule.

You may have heard of something called "the ozone layer." This is a layer of $\mathrm{O}_{3}$ in the stratosphere (the second layer in the earth's atmosphere that sits above the troposphere) that protects people and plants on earth by absorbing harmful ultraviolet radiation from the sun, and is too high up for us to breath in. So "stratospheric ozone" is a good thing, while "tropospheric ozone" is a bad thing. When we talk about "ozone pollution" we're only talking about tropospheric ozone.
Air pollution can lead to health problems such as asthma, lung disease, and sometimes death [1]. Young children and the elderly are more susceptible to health effects from air pollution. Research scientists study air quality, or the amount of pollution in the air, and connections between sources of air pollution and the effect of pollution on human health.

Man-made pollution in the atmosphere can be caused by gases and particles released from combustion sources. Combustion is the process by which a substance that contains energy is burned to release that energy. Some substances commonly used in combustion processes include fossil fuels like gasoline, diesel, coal, and natural gas. Energy obtained from burning fossil fuels provides electricity for our homes and also powers our vehicles. When a fuel is combusted, some chemicals are released as byproducts. These byproducts are called "emissions." Emissions released from combustion sources contribute to "ambient air pollution" or the concentrations of various gases and particulates in the air that we breath.

Since Earth's atmosphere is made of mostly nitrogen and oxygen, most emissions are in the form of compounds made up of nitrogen and oxygen molecules, called nitrogen oxides (or $\mathrm{NO}_{\mathrm{x}}$ ). Because most of the energy sources that we burn are made of carbon, other byproducts are emitted as carbon compounds, including elemental carbon (EC), also known as soot. Emissions like $\mathrm{NO}_{\mathrm{X}}$ can react with other gases already in the atmosphere, like carbon-based gaseous substances called volatile organic compounds (or VOCs), which are emitted naturally from trees and also from human-created materials like paint and varnish. The combination of $\mathrm{NO}_{\mathrm{X}}$ and VOCs creates surface level ozone (or $\mathrm{O}_{3}$ ), also called "tropospheric ozone," because the troposphere is the layer of the atmosphere at the Earth's surface. Breathing in $\mathrm{O}_{3}$ at the Earth's surface can damage lung tissue and cause health problems. ${ }^{1}$ While gases like $\mathrm{NO}_{\mathrm{x}}$ and VOCs are invisible to our eyes, EC is in the black smoke we see coming out of big trucks and buses, and also from your campfire. EC is a particulate. Very small particulates are harmful to human health because they can be breathed deep into the lungs and get into the blood stream. Harmful fine particulate matter is smaller than $2.5 \mu \mathrm{m}$ in diameter and is called " $\mathrm{PM}_{2.5}$ ", where PM stands for particulate matter. EC is an example of a $\mathrm{PM}_{2.5}$ that comes directly from combustion, but $\mathrm{PM}_{2.5}$ can also form from reactions between gases in the atmosphere. While particulates are both directly released by combustion and created in the atmosphere, $\mathrm{O}_{3}$ is only formed through chemical reactions in the atmosphere.

In the United States, the Environmental Protection Agency (EPA) regulates air quality through a law called "The Clean Air Act." Part of this law includes using scientific analysis to determine what concentrations of air pollutants are 
FINE PARTICULATE MATTER (PM 2.5$)$

Liquid and solid compounds smaller than $2.5 \mu \mathrm{m}$ in diameter that contain both carbon and non-carbon pollutants.

\section{AMBIENT AIR}

\section{QUALITY}

The measure of how polluted (poor air quality) or clean (good air quality) outdoor air is.

\section{COMMODITIES}

Food and goods consumers purchase and use in their day-to-day lives, and materials used in manufacturing.

\section{FREIGHT}

Commodities like food, clothing, building materials, electronics, equipment, and many other items that are transported by truck, train, or airplane.

safe for human health. These standards are called the "National Ambient Air Quality Standards." There are different standards for the six pollutants that are considered to be most harmful $-\mathrm{O}_{3}, \mathrm{NO}_{2}, \mathrm{PM}_{2.5}$, sulfur dioxide, carbon monoxide, and lead. Since the Clean Air Act began regulating air quality in 1970, concentrations of these six pollutants have decreased; however, concentrations of $\mathrm{O}_{3}$ and $\mathrm{PM}_{2.5}$ still remain unhealthy and problematic for some cities, especially southern California and the eastern US places that have higher levels of air pollution than are considered safe by the EPA are required to develop plans to reduce their air pollution.

To help determine what activities will help reduce air pollution in an area, scientists can conduct air quality experiments using powerful computers and computer modeling. These models simulate pollution emitted by cars, trucks, trains, and other sources and also simulate the chemical processes in the atmosphere that cause pollutants like $\mathrm{O}_{3}$ to form. These models include complex equations related to the atmosphere, as well as pollution transport by wind, production and destruction by chemical reactions, and removal from the atmosphere through precipitation. These computer models require lot of data inputs, including weather information (also known as "meteorology") and information about emissions from all human and natural sources.

\section{HOW CAN TRANSPORTATION AFFECT AIR POLLUTION?}

One major source of pollution-causing emissions is transportation [2]. Transportation includes cars, trucks, motorcycles, trains, airplanes, and ships. There are two main types of transportation; one is transporting people, known as "passenger transport," and the other is transporting commodities like food, clothing, building materials, electronics, equipment, and many other items, known as "freight transport." In the United States, trucks, trains, ships, and some airplanes are used to transport freight to factories that build things and to stores where we shop. Trucks and trains are powered by engines that require energy to operate, and these engines produce emissions from burning fuel. Emissions from transportation can be quantified, or calculated, from information like the number of trucks and trains operating on roads or railroad tracks, combined with information about how their engines operate and how much pollution they emit per mile traveled during warm or cold times of the year. This information can be used to estimate the total emissions from freight transport each year.

Because freight transportation can have a negative impact on air quality, "Is there a way to reduce emissions and improve the air we breathe by changing how we transport freight?" To answer this question, we created an experiment to analyze how moving more freight by railroad and less by truck could affect air quality in the Midwest United States. For this analysis, we first looked at 
changing commodity transport from truck to railroad just between cities within the Midwest states, for example, moving freight from Minneapolis, MN, USA to Detroit, MI, USA (Scenario 1). Next, we added freight moving through the Midwest region as well, for example, freight moving from California to New York traveling on Midwest roads and railways (Scenario 2). The results of both scenarios are compared to a "Baseline Scenario" that represents how freight is normally transported, which allows us to understand the changes seen in our experimental scenarios.

It is important to know that not all freight can easily move by either truck or train. Typically, train transport can be slower, because individual train cars are combined along the transport route to make long trains (sometimes with 100-200 train cars) that can be transported more efficiently and at lower costs. Because of this, the routes are often not direct. On the other hand, trucks can travel directly from their origin to their destination with no stops, getting there faster. Therefore, fresh produce or seafood might spoil before it arrives at its destination, if transported by train. However, commodities, like car parts, furniture, or sand, do not spoil and can be moved by either truck or train. In addition, when a business is considering whether to transport its goods by truck or train, the owners are going to consider how much transportation will cost them. Generally, railroad transport is cheaper over longer distances, and truck transport is cheaper over shorter distances. For the experimental scenarios in this analysis, we only considered moving goods by train instead of truck if (1) it was possible for the type of commodity and (2) the commodity was being transported further than 400 miles. Figure $1 \mathrm{~A}, \mathrm{~B}$ show the roads and railways where more railroad freight transport was added (in blue) and where truck freight transport was reduced (in red), for each scenario. In Scenario 1, 876 railcars replace 2,534 trucks per day; in Scenario 2, 37,854 railcars replace 103,450 trucks per day. Each of these emissions scenarios (Baseline, Scenario 1, and Scenario 2) was investigated using a computer model with meteorology data to determine the air pollution impacts of moving some freight transport off of trucks and onto trains. The only thing that is different between these scenarios is the emission, because the emission is a direct result of changing the number of trains and trucks used.

Our hypothesis for this experiment is that using more train transportation on railways and less truck transportation on highways means that emissions will increase along the red lines and decrease along the blue lines in Figure $1 \mathrm{~A}, \mathrm{~B}$ and because freight trains can carry more goods per gallon of fuel used, air quality across the entire Midwest will improve. For the first part of our hypothesis, this is exactly the change in transportation emissions that we saw when we compared Scenario 1 and Scenario 2 to the Baseline Scenario (Figures $1 \mathrm{C}-\mathrm{F})$, where increases in emissions per day are colored red and decreases in blue. The changes in emissions for $\mathrm{NO}_{2}$ (Figures 1C) and primary $\mathrm{PM}_{2.5}$ (Figures 1E) in Scenario 1 show that, compared the Baseline Scenario, railway emissions generally increase and highway emissions generally decrease. This 


\section{FIGURE 1}

The top two panels show highway (blue lines) and railway (red lines) routes for $\mathbf{A}$. Scenario 1 and $\mathbf{B}$.

Scenario 2, where changes in all emissions are only made along these paths. The bottom four panels show the daily average emissions changes in kilogram per day from the Baseline for Scenario 1 (left two panels) and Scenario 2 (right two panels) for the month of July. Although all pollutant emissions are modified for the scenarios, here we show the changes for just two pollutants: $\mathrm{NO}_{2}$ B,C and

$\mathrm{PM}_{2.5} \mathbf{E}, \mathbf{F}$. Note that each of the panels $\mathbf{C}-\mathbf{F}$ is shown on different color scales. But in all panels, emissions reductions shown in blue tend to occur along highways, while emissions increases shown in yellow and red tend to occur along railways, with the darker blues and reds indicative of the greatest emissions changes. These changes occur because of the changes in fuel type associated with trains versus trucks. Emissions changes overall tend to be smaller for Scenario 1 (left two panels) and greater in Scenario 2 (right two panels). Figure adapted from Bickford et al. [3].
A Scenario 1 Freight Paths

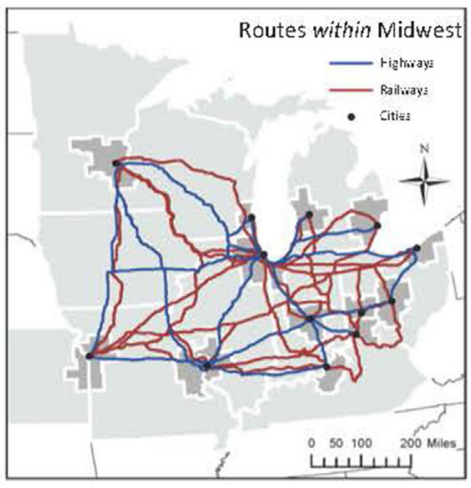

C Change in $\mathrm{NO}_{2}$ Emissions

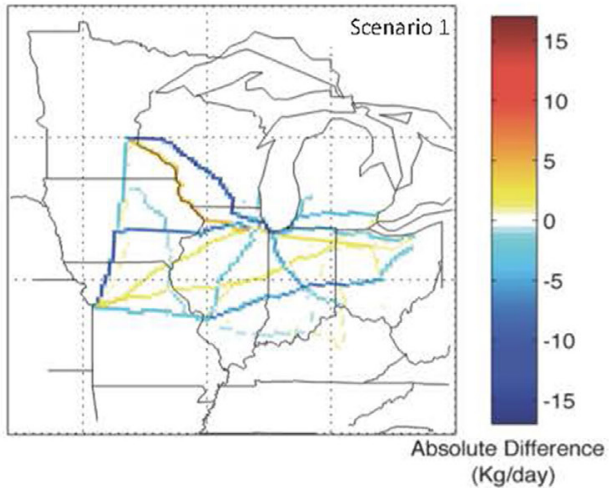

E Change in $\mathrm{PM}_{2.5}$ Emissions

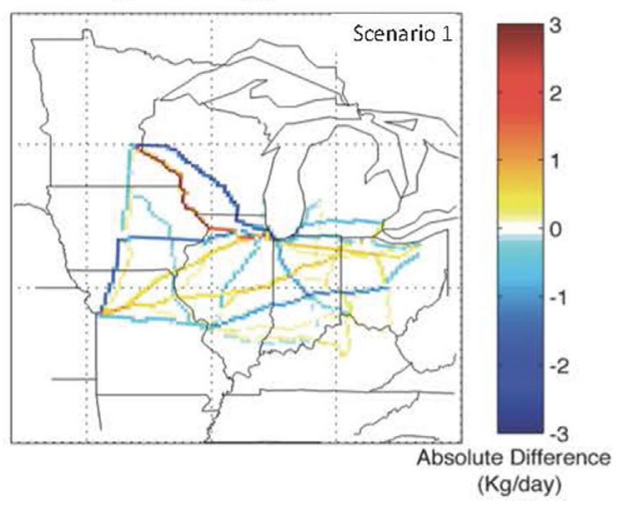

B Scenario 2 Freight Paths

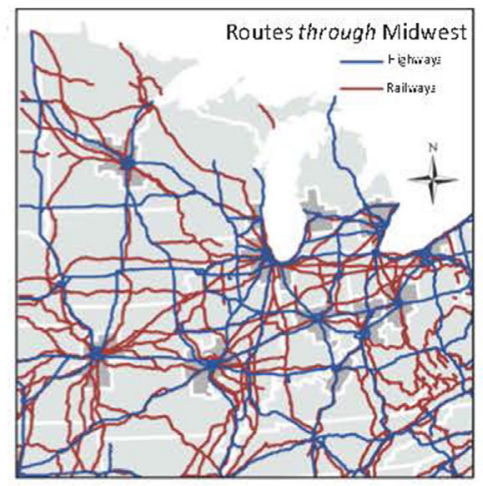

D Change in $\mathrm{NO}_{2}$ Emissions

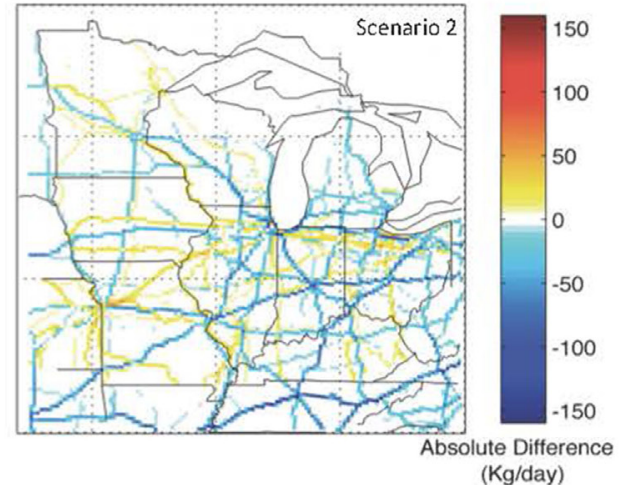

$\mathbf{F}$ Change in $\mathrm{PM}_{2.5}$ Emissions

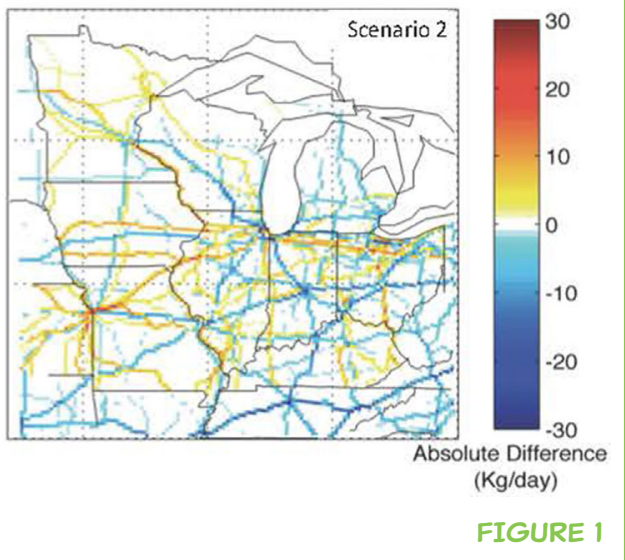

trend is repeated across the whole Midwest in Scenario 2 for $\mathrm{NO}_{2}$ (Figures $1 \mathrm{D}$ ) and primary $\mathrm{PM}_{2.5}$ (Figures $1 \mathrm{~F}$ ) emissions.

Figure 2 shows the percent changes in concentrations of the pollutants $\mathrm{NO}_{2}$ and EC as a result of Scenario 2, in which freight is moving through the Midwest region. Results for Scenario 1, where freight is moving between cities in the Midwest, are not shown, because percent changes in pollutant concentrations were less than $1 \%$. Notice that, compared with Figures $1 C, D$ changes in air quality shown in Figures 2A,B are more spread out across the region, instead of right on top of the roadways and railways. This is because pollution that is 


\section{FIGURE 2}

The percent difference in Scenario 2 from the baseline for the pollutants A. $\mathrm{NO}_{2}$ and $\mathbf{B}$. EC. Increases in concentrations are in red, and decreases in concentrations are in blue, where darker blues and reds indicate the greatest changes. Generally, greatest increases in $\mathrm{NO}_{2}$ concentrations are found along railways, for instance along the Mississippi River at the border of Minnesota, lowa, and Wisconsin, and greatest decreases in concentrations are found along highways, for instance those within the states of Missouri and Michigan. This occurs because in Scenario 2, emissions are removed from highways and added to railways. Reducing emissions from railways and increasing them on highways causes an increase in EC concentrations in $\mathbf{B}$. as a result of the changes in transportation mode fuel type. Note the color scales are different; the maximum and minimum for $\mathbf{A}$. are +30 and $-30 \%$, respectively, and the same for B. are +27.5 and $-27.5 \%$, respectively. Figure adapted from Bickford et al. [3].

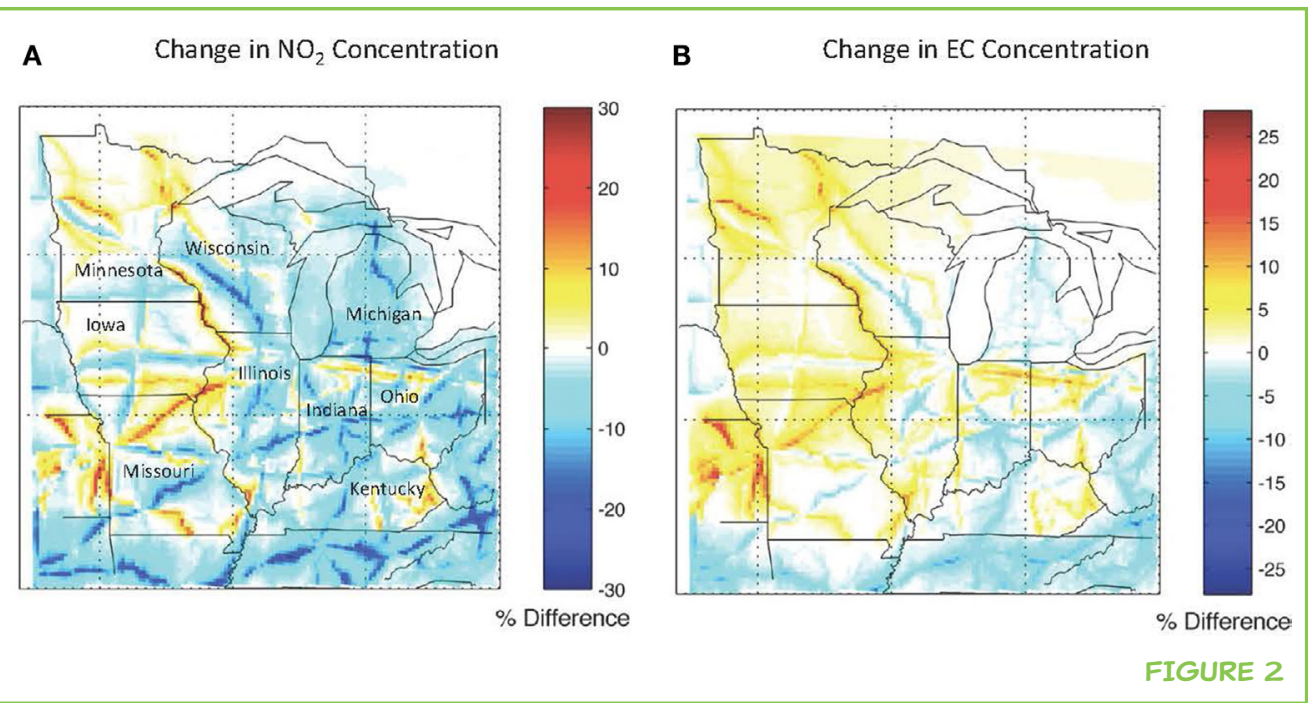

directly emitted from trucks and trains are considered to occur in-place along railways and highways (as shown in Figure 1), which are then acted upon by weather, such as wind speed and directions and precipitation, and chemical production and destruction in the atmosphere, which creates ambient pollution (as shown in Figure 2). However, the greatest changes in air quality still follow the shapes of the roadways and railways, where changes in emissions occur between Scenario 2 and the Baseline. For instance, in the state of Wisconsin, large increases in $\mathrm{NO}_{2}$ and $\mathrm{EC}$ are found along the Mississippi River, where there is a railway, and large decreases are found along the highway in the center of the state. These changes are also very noticeable in Missouri and eastern Kansas. You can also see that, although $\mathrm{NO}_{2}$ concentrations in Scenario 2 dropped close to highways, EC concentrations actually increased a bit, but were more spread out (Figure 2B). This demonstrates how difficult it can sometimes be to solve air quality problems; making a change like using more trains and less trucks for freight transport can make some air pollution problems better, but may also make others worse. Air pollution is especially difficult because the problem is caused not only by the particulates and gases directly emitted by fossil fuel combustion but also how those particulates and chemicals interact with meteorological conditions and chemicals in the atmosphere to create other pollutants. For freight transport in the Midwest, seeing the best improvement in air quality may require a combination of changing freight transport from truck to railroad and changing the type of engines or diesel fuel used by trains.

\section{AIR QUALITY STUDIES CAN HELP COMMUNITIES}

This study shows how we can increase our understanding of how different human activities, like transportation, contribute to ambient air pollution. This helps both scientists examining air quality within a region, as well as air 
quality regulators at the US EPA who are in charge of monitoring air quality for public health purposes. For instance, by observing what kind of changes are introduced by modifying transportation emissions to reduce highway truck transport and increase train transport, we are able to estimate that emissions of $\mathrm{NO}_{2}$ and primary $\mathrm{PM}_{2.5}$ decrease near highways and increase near railways. Information regarding changes in ambient concentrations is valuable to communities who need to reduce their air pollution to protect public health, where even small changes locally can have an influence on whether a community succeeds or fails to achieve EPA's air quality standards.

\section{ORIGINAL SOURCE ARTICLE}

Bickford, E., Holloway, T., Karambelas, A., Johnston, M., Adams, T., Janssen, M., et al. (2014). Emissions and air quality impacts of truck-to-rail freight modal shifts in the Midwestern United States. Environ. Sci. Technol. 48, 446-54. doi:10.1021/ es4016102

\section{REFERENCES}

1. Burnett, R. T., Pope, C. A., Ezzati, M., Olives, C., Lim, S. S., Mehta, S., et al. 2014. An integrated risk function for estimating the global burden of disease attributable to ambient fine particulate matter exposure. Environ. Health Perspec. 122, 397-403. doi:10.1289/ehp.1307049

2. EPA. 2014. U. S. Air Emissions Sources: Nitrogen Oxides. US Environmental Protection Agency.

3. Bickford, E., Holloway, T., Karambelas, A., Johnston, M., Adams, T., Janssen, M., et al. 2014. Emissions and air quality impacts of truck-to-rail freight modal shifts in the Midwestern United States. Environ. Sci. Technol. 48, 446-54. doi:10.1021/ es4016102

SUBMITTED: 05 October 2016; ACCEPTED: 05 February 2018; PUBLISHED ONLINE: 28 February 2018.

EDITED BY: Mark Alan Brandon, The Open University, United Kingdom

CITATION: Karambelas A and Bickford E (2018) Trucks versus Trains: How Does the Way We Get Our Stuff Affect Air Pollution? Front. Young Minds 6:06. doi:10.3389/ frym.2018.00006

CONFLICT OF INTEREST STATEMENT: The authors declare that the research was conducted in the absence of any commercial or financial relationships that could be construed as a potential conflict of interest.

COPYRIGHT (C) 2018 Karambelas and Bickford. This is an open-access article distributed under the terms of the Creative Commons Attribution License (CC BY). The use, distribution 
or reproduction in other forums is permitted, provided the original author(s) and the copyright owner are credited and that the original publication in this journal is cited, in accordance with accepted academic practice. No use, distribution or reproduction is permitted which does not comply with these terms.

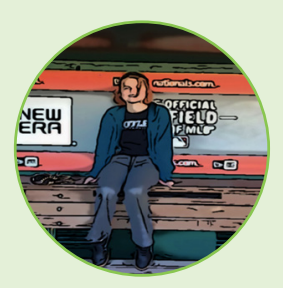

\section{REVIEWED BY}

\section{KIMBERLY, AGE: 16}

I am currently a high school junior. I have been a huge STEM person since I can remember and have recently narrowed my interest down to astrophysics or aerospace engineering. I have always enjoyed reading scientific articles when they were assigned in school, so I find the FYM website to be a great way to motivate myself to read for fun, not for class. I once read an article in class that was talking about rats, but calling them mice! I wish I could have offered them a review.

\section{AUTHORS}

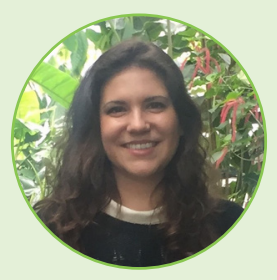

\section{ALEXANDRA KARAMBELAS}

Alexandra Karambelas is a postdoctoral researcher at Columbia University. Her research focuses on the links between energy, emissions, air quality, and human health impacts in India. Through this research, she seeks to quantify the effect man-made emissions like cars and power plants have on pollutant concentrations in the atmosphere and identify the impacts on human health in the region. In this way, she hopes to identify ways to reduce emissions, improve air quality, and reduce negative health effects. Alex received her Ph.D. in Environment and Resources and also holds degrees in Atmospheric and Oceanic Sciences (B.S., M.S.), all from the University of Wisconsin-Madison. *ak4040@columbia.edu

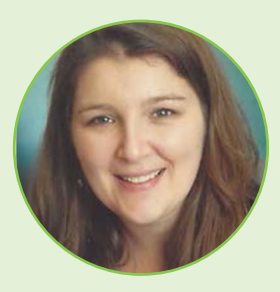

\section{ERICA BICKFORD}

Erica Bickford is the Transportation Program Manager for the US Department of Energy (DOE) Office of Nuclear Energy's Nuclear Fuels Storage and Transportation Planning Project and is responsible for spent fuel transportation policy and planning. Erica began at DOE as an American Association for the Advancement of Science (AAAS) Science \& Technology Policy Fellow. She is a geoscientist with expertise in freight transportation and geographic information systems (GIS). Erica also spent a year in the US Senate working on energy and environmental policy as a Congressional Science Fellow. 